0960-894X(94)00447-1

\title{
MECHANISTIC STUDIES OF AN ANTIBODY WITH CHORISMATE MUTASE ACTIVITY
}

\author{
Jumi A. Shin and Donald Hilvert* \\ Departments of Chemistry and Molecular Biology \\ The Scripps Research Institute \\ 10666 North Torrey Pines Road \\ La Jolla, CA 92037
}

\begin{abstract}
Antibody 1F7 catalyzes the rearrangement of chorismate to prephenate. Its kinetic parameters are unaffected by changes in $\mathrm{pH}$ and display no solvent isotope effect or effects from addition of various cationic salts. These results are consistent with high-resolution structural information of 1F7 bound to a transition state analog.
\end{abstract}

The conversion of (-)-chorismate 1 to prephenate 3 was one of the first nonhydrolytic reactions to be catalyzed by an antibody. 1,2 Chorismate mutase accelerates this reaction $2 \times 10^{6}$-fold over background, ${ }^{3}$ and both the thermal and enzyme-catalyzed reactions are believed to be concerted pericyclic rearrangements with chairlike transition states (2).,5 The bicyclic compound 4 (Figure 1), which mimics this conformationally constrained high energy species state, is an excellent inhibitor of the enzyme ${ }^{6}$ and has been used as a template to induce antibodies with significant chorismate mutase activity. ${ }^{1.2}$ One of these catalytic antibodies, 1F7, accelerates the rate of rearrangement by 200 -fold with high enantioselectivity. ${ }^{1,7}$<smiles>C=C(O[C@H]1C=C([C+](=O)[O-])C=C[C@@H]1O)C(=O)[O-]</smiles>

1

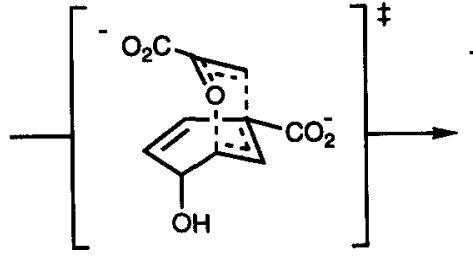

2<smiles>O=C([O-])C(=O)C[C@]1(C(=O)[O-])C=C[C@@H](O)C=C1</smiles>

3 
The three-dimensional structure of 1F7 bound to the transition state analog 4 has recently been determined to $3.0 \AA$ resolution (Figure 1). ${ }^{8}$ The antibody's structural properties accurately reflect those of the transition state analog. Thus the antibody binding site provides an environment with excellent shape and electrostatic complementarity to the conformationally restricted transition state analog; a network of hydrophobic contacts, hydrogen bonds, and electrostatic interactions provide a surface which preferentially binds the correct substrate enantiomer in a reactive conformation. ${ }^{9}$ The absence of functional groups in the active site that could form a covalent intermediate with the substrate or participate in general acid-base catalysis suggests that the antibody catalyzes the reaction by the same concerted pericyclic mechanism as the natural enzyme.

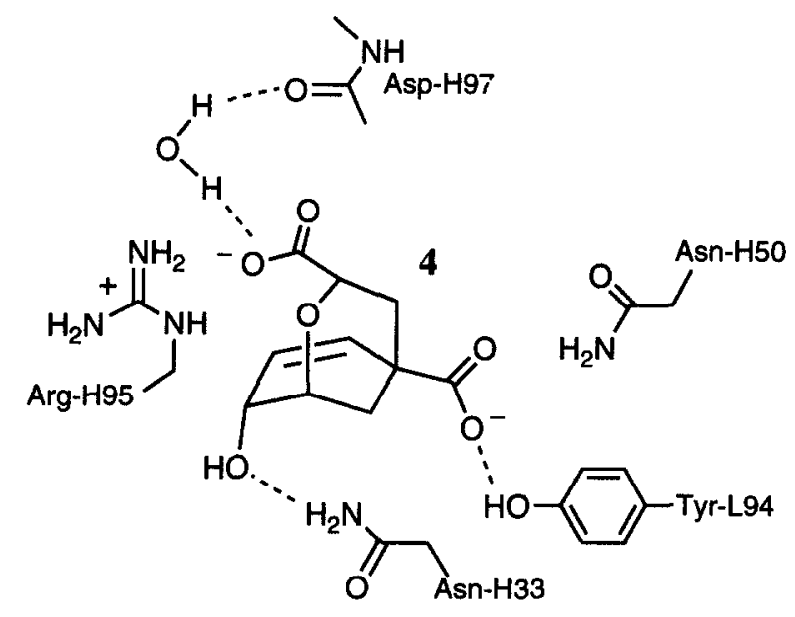

Figure 1. Schematic diagram displaying the hydrogen bonding and electrostatic interactions of the transition state analog 4 with the active site of $1 \mathrm{~F} 7$. Dashed lines indicate hydrogen bonds; bonds are not shown for residues at distances greater than $3.3 \AA$ from the ligand. ${ }^{8}$

Given the availability of detailed structural information, ${ }^{8}$ we have further explored the interactions between the active site of 1F7 and its substrate chorismate. Consistent with the dearth of ionizable groups in the 1F7 active site, we find that the kinetic parameters for the antibody-catalyzed reaction are independent of $\mathrm{pH}$ between pH 6.0 and pH 9.5 (Figure 2). The rearrangement catalyzed by the chorismate mutase isolated from Bacillus subtilis is similarly insensitive to $\mathrm{pH}$ in this range. ${ }^{10}$ Unlike the antibody, however, chemistry is not rate limiting for the enzyme. ${ }^{10}$ 


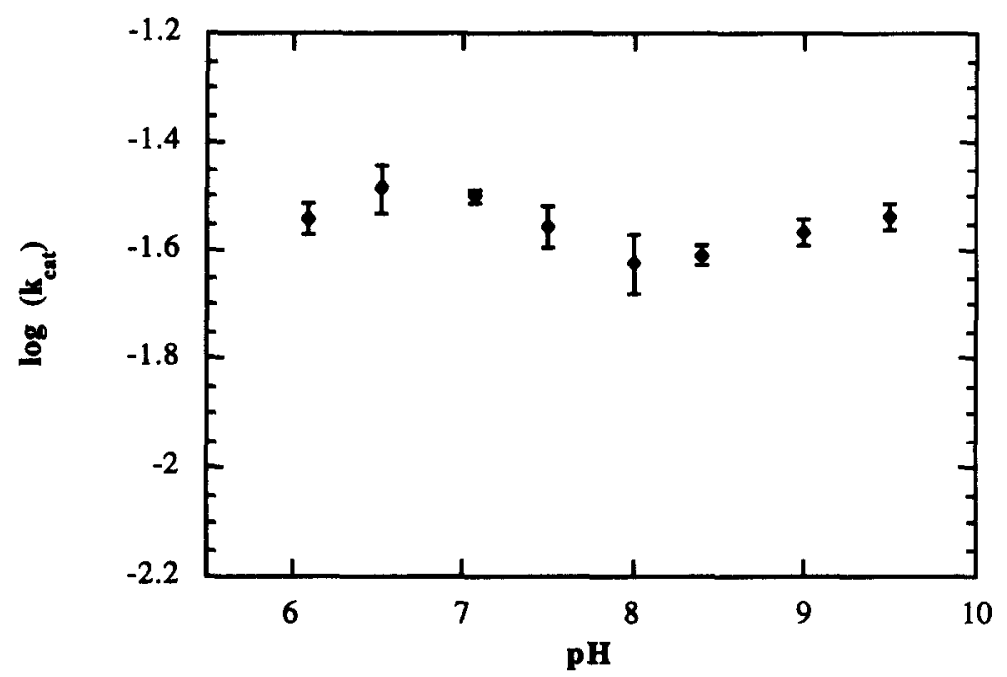

Figure 2. $\mathrm{pH}$ rate profile of 1F7-catalyzed conversion of chorismate to prephenate. Rates are corrected for the uncatalyzed reaction at the appropriate $\mathrm{pH}$. Conversion of chorismate was monitored at $275 \mathrm{~nm}$ in the following buffers: $\mathrm{pH} 6,100 \mathrm{mM}$ His; $\mathrm{pH} 6.5$, pH 7.0, pH 7.5, $100 \mathrm{mM}$ PBS; $\mathrm{pH} 8.0, \mathrm{pH} 8.5,100 \mathrm{mM}$ Tris; $\mathrm{pH}$ 9.0, pH 9.5, $100 \mathrm{mM}$ BBS. All experiments were carried out at $14{ }^{\circ} \mathrm{C}$.

When 4 binds to the 1F7 active site, its secondary carboxylate becomes deeply buried. This moiety appears to form a hydrogen bond to the backbone carbonyl oxygen of Asp-H97 via a water molecule, whereas its negative charge is presumably neutralized by an electrostatic interaction with Arg-H95 (Figure 2). ${ }^{8}$ Solvent kinetic isotope effects were investigated to ascertain whether the putative water molecule plays an important role in catalysis. The solvent isotope effect was measured spectrophotometrically at $275 \mathrm{~nm}$ at pH $7.5(10 \mathrm{mM}$ Tris, $100 \mathrm{mM} \mathrm{NaCl}, 14^{\circ} \mathrm{C}$ ) and corrected for the uncatalyzed rates in the appropriate solvent. No effect on $\mathrm{k}_{\mathrm{cat}}$ was observed [ $\left.\left(\mathrm{k}_{\text {cat }}\right)_{\mathrm{H}_{2} \mathrm{O}} \mathrm{d}\left(\mathrm{k}_{\mathrm{cat}}\right)_{\mathrm{D}_{2} \mathrm{O}}=0.99\right]$, and only a small effect on $\mathrm{K}_{\mathrm{m}}$ was detected $\left[\left(\mathrm{K}_{\mathrm{m}}\right)_{\mathrm{H}_{2} \mathrm{O}} /\left(\mathrm{K}_{\mathrm{m}}\right) \mathrm{D}_{2} \mathrm{O}=\right.$ 1.19]. These results indicate that if a water molecule is important for preorganizing the substrate for catalysis within the active site, it can be replaced with $\mathrm{D}_{2} \mathrm{O}$ with little or no consequence. The lack of a solvent isotope effect again mirrors the behavior displayed by the $B$. subtilis enzyme. ${ }^{10}$

Antibody 1F7 is four orders of magnitude less active than chorismate mutase. Comparison of the threedimensional structures ${ }^{8,11}$ of the two proteins suggests that the enzyme is a better entropy trap and provides greater electrostatic complementarity to the polarizable transition state. These points are illustrated by the different ways the enzyme and antibody interact with the secondary carboxylate of the hapten and, by inference, the enol pyruvate side chain of chorismate. In the case of the antibody, the secondary carboxylate forms a hydrogen bond to the backbone carbonyl oxygen of Asp-H97 via a water molecule. Although Arg-H95 of 1F7 lies near the secondary carboxylate and the ether oxygen, its side chain does not directly contact these functional groups. In contrast, the enzyme active site locks the secondary carboxylate in place through multiple hydrogen- 
bonding contacts via two positively charged arginines (Arg7 and Arg90) and a tyrosine (Tyr108). ${ }^{11}$ Arg90 additionally makes a hydrogen bond to the ether oxygen of the hapten and may contribute to catalysis by stabilizing any negative charge that develops on the ether oxygen during rearrangement of chorismate to prephenate. 8,11

These considerations raise the possibility of improving 1F7's catalytic acitivity by replacing the active site water molecule with an exogenously added ammonium or guanidinium ion to mimic the stabilizing electrostatic interactions provided by Arg90 in the enzyme. The rates of reaction were consequently measured in buffers containing $100 \mathrm{mM} \mathrm{NH} 4 \mathrm{Cl}$ or $100 \mathrm{mM}$ guanidinium $\cdot \mathrm{HCl}$ and corrected for the uncatalyzed rates in the appropriate salt. No effect on $\mathrm{k}_{\mathrm{cat}}$ is detected with either salt $\left[\left(\mathrm{k}_{\mathrm{cat}}\right)_{\mathrm{NH}_{4}} /\left(\mathrm{k}_{\mathrm{cat}}\right)_{\mathrm{NaCl}}=1.02\right.$ and $\left.\left(\mathrm{k}_{\text {cat }}\right)_{\text {guan }} /\left(\mathrm{k}_{\text {cat }}\right)_{\mathrm{NaCl}}=1.02\right]$, although a small effect is observed on $\mathrm{K}_{\mathrm{m}}\left[\left(\mathrm{K}_{\mathrm{m}}\right)_{\mathrm{NH}_{4}} /\left(\mathrm{K}_{\mathrm{m}}\right)_{\mathrm{NaCl}}=1.30\right.$ and $\left.\left(\mathrm{K}_{\mathrm{m}}\right)_{\text {guan }} /\left(\mathrm{K}_{\mathrm{m}}\right)_{\mathrm{NaCl}}=1.35\right]$. It is possible that the antibody active site is unable to accommodate the cations, even though the relatively small ammonium ion might be expected to replace the bound water molecule with relative facility. Alternatively, bound ammonium and guandinium ions may be no better than water at restricting the conformational flexibility of the substrate at the active site.

These studies extend our understanding of antibody 1F7 and are in agreement with all available structural information. 8,9 Although the antibody does not appear to function by a dramatically different mechanism from that of the well-studied enzyme chorismate mutase, there appear to be some important differences. $^{8.11}$ Future efforts to improve the catalytic activity of 1F7 should probably strive to improve complementarity of the antibody to the transition state by redesign of the CDR loop responsible for recognition of the hapten's secondary carboxylate.

Acknowledgment. The authors gratefully acknowledge financial support from the National Institutes of Health GM-38273 and American Cancer Society Postdoctoral Fellowship PF-3761 to J. A. S.

\section{References}

1. Hilvert, D.; Carpenter, S. H.; Nared, K. D.; Auditor; M., M.-T. Proc. Natl. Acad. Sci. USA 1988, 85, 49534955 .

2. Jackson, D. Y.; Jacobs, J. W.; Sugasawara, R.; Reich, S. H.; Bartlett, P. A.; Schultz, P. G. J. Am. Chem. Soc. 1988, 110,4841 .

3. Andrews, P. R.; Smith, G. D.; Young, I. G. Biochemistry 1973, 12, 3492-3498.

4. Sogo, S. G.; Widlanski, T. S.; Hoare, J. H.; Grimshaw, C. E.; Berchtold, G. A.; Knowles, J. R. J. Am. Chem. Soc. 1984, 106, 2701-2703.

5. Copley, S. D.; Knowles, J. R. J. Am. Chem. Soc. 1985, 107, 5306-5308.

6. Bartlett, P. A.; Johnson, C. R. J. Am. Chem. Soc. 1985, 107, 7792.

7. Hilvert, D.; Nared, K. D. J. Am. Chem. Soc. 1988, 110, 5593-5594.

8. Haynes, M. R.; Stura, E. A.; Hilvert, D.; Wilson, I. A. Science 1994, 263, 646-652.

9. Campbell, A. P.; Tarasow, T. M.; Massefski, W.; Wright, P. E.; Hilvert, D. Proc. Natl. Acad. Sci. USA 1993, 90,8663 .

10. Gray, J. V.; Eren, D.; Knowles, J. R. Biochemistry 1990, 29, 8872-8878.

11. Chook, Y. M.; Ke, H.; Lipscomb, W. N. Proc. Natl. Acad. Sci. USA 1993, 90, 8600-8603. 